University of Nebraska - Lincoln

DigitalCommons@University of Nebraska - Lincoln

The Nebraska Educator: A Student-Led Journal Department of Teaching, Learning and Teacher

Education

$10-2020$

\title{
Bilingual Acculturation Assessment: An Overview of Current Developments
}

Donna Chen

University of Nebraska-Lincoln, donna.chen59@gmail.com

Follow this and additional works at: https://digitalcommons.unl.edu/nebeducator

Part of the Bilingual, Multilingual, and Multicultural Education Commons, Educational Assessment, Evaluation, and Research Commons, and the Teacher Education and Professional Development Commons

Chen, Donna, "Bilingual Acculturation Assessment: An Overview of Current Developments" (2020). The Nebraska Educator: A Student-Led Journal. 42.

https://digitalcommons.unl.edu/nebeducator/42

This Article is brought to you for free and open access by the Department of Teaching, Learning and Teacher Education at DigitalCommons@University of Nebraska - Lincoln. It has been accepted for inclusion in The Nebraska Educator: A Student-Led Journal by an authorized administrator of DigitalCommons@University of Nebraska - Lincoln. 


\title{
Bilingual Acculturation Assessment: An Overview of Current Developments
}

\author{
Donna Chen \\ Department of Educational Psychology \\ University of Nebraska-Lincoln
}

\begin{abstract}
Assessments are often used for decision-making in education, mental health practices, and industry. Consequently, decisions based on these assessments affect multiple aspects of a person's life. Given the increase of ethnic minorities in the U.S., factors concerning the appropriateness and interpretation of tests based on norms must be reconsidered. The multifaceted effects of culture are just one factor to consider so as to not overlook important cultural components that may negatively impact the decision-making process. Additionally, language, with close ties to culture, must also be considered. Thus, the complexity of culture and language in tandem to assessment-based decision-making necessitates fundamental understanding of the effects of bilingual acculturation assessment development. A brief history of bilingual acculturation is considered. Careful consideration is given to bilingual acculturation assessment within the context of measurement development, empirical application, and validity issues. Implications and limitations of the current studies are discussed.
\end{abstract}

Keywords: bilingual acculturation assessment, measurement development, ethnic minorities, theoretical/conceptual

doi: 10.32873/unl.dc.ne007 


\section{Bilingual acculturation assessment: An overview of current developments}

Culture is both a messy and a beautiful phenomenon; messy in the sense that it is not easily defined, yet simultaneously beautiful in that it creates a tapestry of rich diversity, woven in to the human race. Culture touches all facets of life. It governs how we speak, the ways we behave, our small mannerisms, to the way we interact with each other. Culture is not a stagnant entity, rather, it shifts dynamically, often more apparent when people of different backgrounds consistently interact with one another. As the ethnic minority populations in the United States continue to increase, currently forming about $23.5 \%$ of the population (U.S. Census Bureau, 2018), people of different cultures come into continuous contact with one another, thereby changing the other's culture through a process known as acculturation - the extent to which a person associates with a given ethnic minority or majority culture (Moyerman \& Forman, 1992).

Given the increase of ethnic minorities in the U.S., factors concerning the appropriateness and interpretation of tests based on norms must be reconsidered, especially when these tests are involved in decision-making (Sandoval, 1998). Norms can be conceptualized as an aggregated score distribution derived and standardized from a large representative sample against which individual performance can be compared. The norms for these tests, often measured and used as a reflection of the average test taker in the population (Sandoval, 1998), may often be based on the majority-group. The implication for drawing from the majority-group is that test scores may not be reflective of individuals outside the majority group. These tests are often used for decision-making in education, mental health practices, and industry, affecting multiple facets of a person's life. Thus, cultural norms must be taken in to account so as to not overlook important cultural components that may negatively impact the decision-making process (Sandoval, 1998). 
An important factor closely tied to cultural norms is acculturation. It is important to consider how a person's acculturation status may affect their performance on tests.

Language is closely tied with culture and must be considered when measuring acculturation (Luna et al., 2008; Marín \& Gamba, 1996; Schwartz et al., 2014). Bicultural bilinguals, individuals who associate themselves with two cultures and speak both languages, have been found to have "distinct cognitive frameworks" when speaking different languages (Luna et al., 2008, p. 279). This phenomenon of switching between frameworks depending on which language is spoken is often referred to as cultural frame-switching (Benet-Martínez et al., 2002; Luna et al., 2008; Schwartz et al, 2014). Thus, the language of a test or assessment may activate certain characteristics, thereby differentiating a bilingual person's results had they taken the test in the other language. It is important to consider how bilingual acculturation assessment is conducted, as it has implications for decision-making when using normed tests.

\section{A Brief History of Bilingual and Bicultural Assessment}

In considering why acculturation measures are so important, two cases are presented that served as critical points in drawing public attention towards consideration of equitable education for culturally, ethnically, and linguistically diverse students. The first case was the Diana v. California State Board of Education (1970) court case. Nine Mexican-American children whose primary language was Spanish were given IQ tests in English and subsequently placed in Special Education classes due to their low scores. The court ruled that California school districts were to test children in their primary language as well as with nonverbal tests (McLean, 1995). Second, the Lau v. Nichols (1974) U.S. Supreme Court case concerned about 1,800 Chinese students in California who were placed into separate "Oriental" English only schools, subsequently to be 
ignored by teachers and school administrators (McLean, 1995). The court ruled that schools must provide equal education to all students, regardless of English language ability.

Although the cases put into ruling what schools should do, positive results adhering to the intentions of the ruling were not immediate. Cummins (1982) reported the continuous disproportionate number of bilingual students who are labeled "low IQ" and placed in special education classes. He notes the bias of applying mental tests that fail to account for cultural and linguistic differences. Additionally, he illustrates the need for school programs to be culturally and linguistically oriented, to include context-embedded approaches towards achieving language proficiency. With a more specific focus on school psychologists' use of testing, Figueroa (1989) brings forth the issue of anomalies in test scores among bilingual students. Again, there is evidence to suggest that, since professionally developed tests are often normed based on norm groups consistent with the United States census, consequences of using such tests on non-norm populations may lead to errors and misdiagnoses. Additionally, norming based on census data does not provide insight into cultural differences within groups. Figueroa (1989) makes the case for the development of appropriate linguistically and culturally-relevant tests for use in schools.

\section{Framework}

To begin, the framework for this paper is built by discussing pertinent key concepts along with their associated issues.

\section{Culture}

First, as discussed earlier, culture is not easily defined. Many social and behavioral scientists have attempted to define culture, each covering slightly different aspects. As Frisby (1998) summarizes, culture has been defined to include personality (Kroeber \& Kluckhohn, 1952); shared learning across generations (Rohner, 1984); "the totality of ideals, beliefs, skills, 
tools, customs, and institutions into which each member of a society is born" (Sue \& Sue, 1990, p. 35); as well as "some combination of differences in skin color, country of origin, language, customs, socialization priorities, and sometimes socioeconomic class" (Triandis \& Brislin, 1984, p. 1007). Indeed, the definition of culture for this paper is based on an amalgamation of these definitions, which becomes apparent throughout the paper, as it was found that different studies focus on different aspects of culture as a measure of acculturation.

\section{Acculturation}

The most often cited framework for understanding acculturation is John Berry's (1980) four acculturation profiles: integration, assimilation, separation, and marginalization.

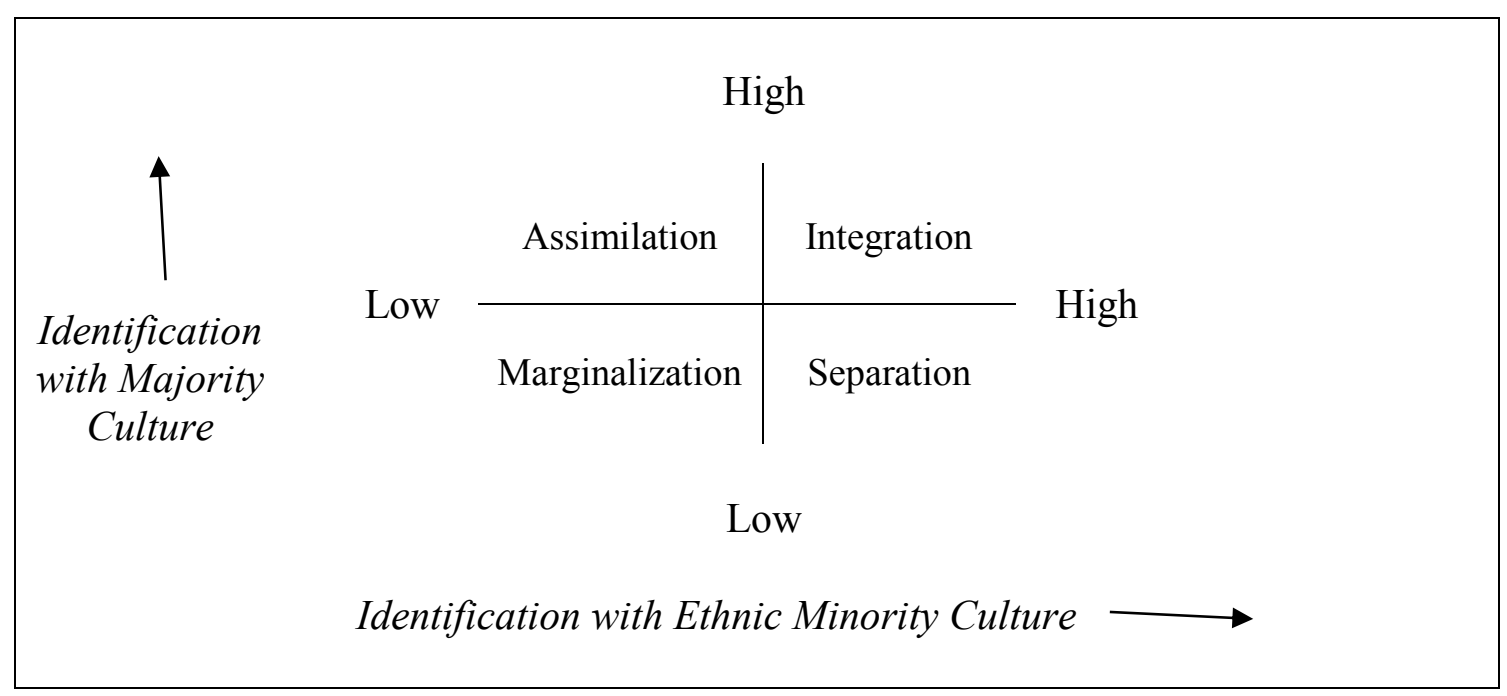

Figure 1. Visual display of Berry's (1980) four acculturation profiles.

Each of these are considered from the basis of how much a person values and identifies with the ethnic group versus the dominant (or majority) group. Figure 1 is a visual display of how these four acculturation profiles relate to each other. Integration occurs when a person values both their ethnic and majority culture, finding a complementary view for having both, often referred 
to as biculturalism. Assimilation is when the person values only the majority culture, having either a low or no value or identification with their ethnic culture. Separation, on the other hand, is the manifestation of only valuing the ethnic culture while disassociating with the majority culture. Marginalization is when the individual rejects the values of both the ethnic and majority cultures.

Follow-up studies with different ethnic minority groups have demonstrated different, or separate, acculturation groups from those originally proposed by Berry (1980). For example, in a study with Chinese Canadian university students, Chia and Costigan (2006) identified five acculturation groups instead of four. Schwartz and Zamboanga's (2008) study with Hispanic college students found six latent classes emerged from the analyses. This discrepancy in findings suggests that the true nature of acculturation cannot be easily pinned down and may even differ by ethnicity groups. Since acculturation measures are used for a variety of purposes (e.g., determining a student's educational placement or allotment of additional educational resources or services; determining mental health status; determining language of assessment, etc.), often having a major impact on people's lives, there is need to more carefully examine how acculturation is being measured.

\section{Biculturalism}

Biculturalism, or Berry's integration profile, is the endorsement of both the culture of origin as well as the receiving culture, often manifested as identification with both the ethnic minority and majority (Chen et al., 2008; Schwartz \& Unger, 2010; Van de Vijver \& Phalet, 2004). Initial attempts at measuring biculturalism included considering proficiency and comfort in both languages, choice in friends, media preferences, etc. (Schwartz \& Unger, 2010). Progress in the area then led to a broader consideration of biculturalism to include the cultural practices 
that an individual may partake in, the values from each culture that the individual adheres to, as well as which culture, or both, the individual identifies with (Schwartz \& Unger, 2010). With different perspectives for this subject, Basilio et al. (2014) continued to extend biculturalism towards encompassing more psychological constructs such as identity, beliefs, attitudes, and response towards cultural cues.

Even within biculturalism, there are differences in how individuals perceive the compatibility and complementarity of their cultures - known as bicultural identity integration (BII; Benet-Martínez et al., 2002). While some bicultural individuals see their two cultures as being compatible and complementary, others may perceive their two cultures to contradict in their meaning systems. Benet-Martínez et al. (2002) conducted a study that revealed BII to be a moderator for the effects of cultural frame shifting - unconscious behavioral switches, or frame of thinking, primed by cultural cues - on measures of acculturation. In instances where the two cultures are perceived to be incongruent (e.g., individualistic versus collectivistic cultural values), the focus is on how bicultural individuals negotiate those oppositional values. When given certain cultural primes or cues, an individual is more or less likely to respond in a way that is congruent to the culture of the primes. Thus, assessments that ignore levels of acculturation face issues of validity.

Comas-Diaz and Grenier (2002) briefly outline some of the existing measures of acculturation, many of which are culture specific. Some examples include the Acculturation Rating Scale for Mexican Americans I (Cuéllar et al., 1980) and II (Cuéllar et al., 1995), the Behavioral acculturation Scale for Cubans (Szapocznik et al., 1978), the Suinn-Lew Asian SelfIdentity Acculturation Scale (SL-ASIA; Suinn et al., 1987), and the Acculturation Scale for American Indian Adolescents (King \& Keane, 1992). These examples illustrate that within some 
of the largest ethnic minority groups (i.e., Hispanic/Latino, Asian), there are many sub-cultures that vary vastly. Each of these culture-specific scales make it difficult for researchers to generalize the results to other ethnic groups. There remains, however, the reality that creating an acculturation scale to fit all existing cultures is extremely difficult. Due to the dissonance between studies in minority ethnic groups, failure to account for acculturation status results in violations of reliability and validity (Padilla, 2001). Therefore, the question becomes, what work has been done to ameliorate these discrepancies? This paper will review developments in bilingual acculturation assessments, validity and reliability issues, as well implications for these considerations.

\section{Methods}

The search phrases bilingual assessment, acculturation assessment, and bilingual acculturation assessment were entered into various search engines and databases, including Google Scholar, Academic Search Premier, and PsycInfo (EBSCOhost). Articles were selected based on their relevance to the topic of this paper.

\section{Results}

The articles that were found can be categorized to two sections: measure development and empirical work.

\section{Measure Development}

\section{Hispanic Ethnic Groups}

The Acculturation Rating Scale for Mexican Americans (ARSMA; Cuéllar et al., 1980) was developed by giving a sample of Mexican Americans a measure in English and Spanish, scored on a 5-point Likert scale: Very Mexican, Mexican-Oriented Bicultural, True Bicultural, Anglo-Oriented Bicultural, and Very Anglicized. This rating scale was a popular measure, often 
used to assess acculturation and mental health status. In fact, the ARSMA was initially developed with the purpose of having a measure of acculturation that would serve as a moderator variable in clinical practice to help explain differences found in ethnic minority groups compared to the majority group (Cuéllar et al., 1995). The ARSMA measured four main factors: (a) the extent to which Mexican Americans used Spanish versus English along with their preference, (b) how they perceived their ethnic identity and to which classification they placed themselves, (c) cultural heritage and ethnic behaviors they exhibited, and (d) ethnic interaction (Cuéllar et al., 1980).

Cuéllar et al. (1995) noted several criticisms of the ARSMA, one major criticism being that acculturation was treated as unidimensional, or in a zero-sum manner, with Mexican culture and American culture on opposite ends of the linear representation. The assumption was that to move towards one cultural extreme was to lose aspects of the other culture. Additionally, the Likert scale provided no way of detecting marginalization - low identification with both cultures. Therefore, the ARSMA-II was developed to address these criticisms (Cuéllar et al., 1995). The ARSMA-II was a revised version that took a multidimensional approach to acculturation, based on a framework resembling Berry's (1980) four acculturation profiles rather than a linear representation of two cultural extremes.

With the development of these measures, however, there were still overarching issues not addressed by the measurement developers. Namely, authors incorrectly incorporated demographic indicators as part of the construct which thereby increased validity. Authors also tended to only use one Hispanic subgroup or validated some scales (e.g., ARSMA-II) using only college students, two practices which limit generalizability. Finally, with the inclusion of 
multiple scales within a measure, data reduction techniques, such as factor analysis, were not used to decide which items belong to which scale (Marín \& Gamba, 1996).

Marín and Gamba (1996) developed the Bidimensional Acculturation Scale for Hispanics (BAS) to address some of the methodological limitations in these previous scales. The primary components of the BAS that differentiate it from previous measures was that 1) participants were recruited and interviewed over the phone, thus not relying on college students, 2) a multidimensional framework was used in lieu of the linear conceptualization, and 3) subscales for different areas of acculturation were created using factor analysis, where previous measures either relied on single items for each domain, or did not use data reduction techniques to create scales within the measure (Marín \& Gamba, 1996). The authors assert that the measure was valid for Mexican Americans and Central Americans.

Basilio et al. (2014) developed another biculturalism scale for Mexican American adolescents and adults from a psychological perspective. Basilio et al. (2014) made the argument that existing measures of acculturation were based on demographic variables, such as exposure to language, ethnic practices, and other cultural influences. To address these shortcomings, they proposed measuring biculturalism on psychological constructs (e.g., identity, behavior, beliefs, attitudes, values, worldview, and ability to respond to cultural cues). In particular, Basilio et al. (2014) designed a measure to assess the bicultural elements of emotion, behavior, and cognition. Someone who is bicultural is hypothesized to feel comfortable, behave appropriately, and perceive advantages to being associated with both cultural contexts. This framework also taps into cultural frame switching and offers a starting point in considering how to measure and conceptualize unconscious responses that can be triggered with cultural cues.

\section{Asian Ethnic Groups}


In 2001, the ratio of the number of measures for Hispanic groups to the number of measures for Asian Pacific American groups was 27:4 (Kim \& Abreu, 2001). The most prominent measure for Asian American acculturation was the SL-ASIA (Suinn et al., 1987). Similar to the original ARSMA, the SL-ASIA assessed acculturation from a unidimensional standpoint. Given this limitation, Chung et al. (2004) developed the Asian American Multidimensional Acculturation Scale (AAMAS), which took a bidimensional approach to create an instrument that could be used with multiple Asian ethnic groups. In striving for applicability towards multiple Asian ethnic groups, Chung et al. (2004) raise the concept of pan-ethnicity, a third dimension not explored in previous studies.

Pan-ethnicity refers to a general "solidarity" among ethnic subgroups, often caused by categorization of subgroups to form one larger group (e.g., Koreans, Japanese, Thai, Malay, Indonesian, Taiwanese, Indian, etc., all collectively referred to as "Asians"). Pan-ethnicity is manifested when individuals of subgroups lay aside their subgroup differences to identify with the overall pan-ethnic culture (Chung et al., 2004). Pan-ethnicity is important to consider because individuals of subgroups, perhaps while acculturating to the majority culture, may also be acculturating towards a pan-ethnic culture. This means that they are not quite adhering to their culture of origin, rather, to a new culture only formed by a collection of subgroup interactions. Thus, the authors of the AAMAS strived to include a measure of pan-ethnic identification as part of acculturation. The measure consists of three scales: AAMAS-Culture of Origin (AAMASCO), AAMAS-Asian American (AAMAS-AA), and AAMAS-European American (AAMASEA).

The authors found that the AAMAS revealed a four-factor structure: cultural identity, language, cultural knowledge, and food consumption. A limitation of this measure was the 
difficulty in validating pan-ethnic dimensions due to a lack of previous work on the concept. The authors hypothesized that pan-ethnicity would be related to two factors: (a) length of residence and opportunities to interact with other subgroups within the context of the host culture, and (b) derivation of some shared cultural base in similarity of experiences in the host culture. To demonstrate validity for the pan-ethnic dimension, the authors explained that the correlation patterns between the AAMAS-AA and the other previously validated measures showed similar patterns compared to AAMAS-CO, but to a lesser extent. For example, someone with a strong positive correlation between AAMAS-CO and SL-ASIA would also have a positive correlation between AAMAS-AA and SL-ASIA, but of a lesser magnitude (Chung et al., 2004).

\section{Ethnic Minorities Around the World}

Until this point, the majority of reviewed literature has existed in examining ethnic minority acculturation in the U.S. From a global standpoint, migration movements have led to increased cultural diversity in many countries. Relocating in any capacity increases the need for mental health practitioners to understand migration effects on psychological functioning, as well as how to interact and care for a more diverse population (Eytan et al., 2007). Additionally, Eytan et al. (2007) emphasized a need for an instrument that is, among other criteria, brief, multidimensional, bi-directional, and multiethnic. This measure was developed in Switzerland and validated with immigrant adults from Italy, Portugal, and Spain. One important aspect the authors brought forth was the potential to use this scale, not necessarily for people of the same ethnic groups, but for immigrants with similar motivations for migrating. This measure, in particular, was designed for immigrants who migrated based on economic reasons. It was also created for the more specific purpose of use in clinical purposes by mental health professionals.

\section{Empirical}


Acknowledging the two different frameworks for acculturation (unidimensional versus multidimensional), Abe-Kim et al. (2001) considered different scoring procedures as a way of considering unidimensional versus multidimensional perspectives. Asian American undergraduates were asked to take the SL-ASIA. The authors considered major cultural indicator variables (i.e., individualism-collectivism, independent-interdependent self-construal, loss of face, and impression management) that mark differentiation between the Asian and American cultures. Accordingly, the SL-ASIA was scored to either reflect the unidimensional or the bidimensional framework. The authors found that generational status can be used as a proxy only if acculturation is viewed from a unidimensional perspective. If, however, acculturation is considered the amalgamation of a set of cultural orientations, then generational status cannot and should not be used as a proxy variable.

In assessing acculturation using the bidimensional approach, researchers assume that identifying with one culture is not dependent on identification with the other culture. Therefore, there is independence, or orthogonality, in the maintenance of ethnic identity (Kang, 2006). There exist anomalies in the findings such that some studies revealed a violation of the independence assumption. Three scale formats are often used to assess different domains of acculturation. Frequency (e.g., "How much do you speak [language] at home?" "How often do you eat [culture] food?") is used to assess a number of different domains, but is most often used to assess language use. Proficiency (e.g., "How well can you speak [language]?”) is also most often used to assess language proficiency. Endorsement (e.g., "I am proud of [culture] culture." “I celebrate [culture] holidays.”) often measures attitudes, values, or preferences. Kang (2006) points out a few major findings of acculturation studies that may be affecting the lack of orthogonality in findings. First, frequency formats are most suited for measuring use. The issue, 
however, is that acculturation is more than language use. Using proficiency formats often aggravates the problem, as proficiency in one language often triggers a lower proficiency in the other language. Previous research suggests, then, that the endorsement format would be the most appropriate way of validly measuring acculturation.

Kang (2006) tested the hypothesis that scale format affects orthogonality by giving a group of Asian American university students the General Ethnicity Questionnaire (GEQ; Tsai et al., 2000) to measure acculturation. The GEQ was selected because all three scale formats were included, which allowed for the hypothesis (endorsement vs. frequency/proficiency) to be tested. Additionally, the GEQ has two versions: GEQ-American (AM) and GEQ-Asian (AS), differing only in the reference culture. Examining correlations between the different sections and versions, the results revealed a small correlation between versions (AM vs. AS) for endorsement items, while frequency and proficiency formatted items had strong correlations between measure versions. They concluded that there is sufficient evidence to suggest frequency and proficiency scale formats are contributing to the lack of orthogonality found in some studies.

Previous research has shown the effects of priming using cultural icons and symbols on acculturation measures. Lechuga (2008) examined the effects of priming on bilingual Mexican American college students. Participants were recruited based on the ability to read, write, and speak both languages (English and Spanish). They were randomly assigned to receive either Mexican or American cultural primes (e.g., flag, icons, food, monuments, etc.) before being asked to fill out a questionnaire including measures of language proficiency, self-construal (collectivistic vs. individualistic views), and ethnic identity and acculturation/enculturation. The results support the hypothesis that priming affects how participants self-identify their ethnic categorization. The main limitation in this study, however, was its basis in the measure of 
language proficiency. The authors misplaced emphasis on language proficiency as a measure of acculturation and failed to consider psychological constructs that may be affected by cultural priming.

The majority of research in acculturation has taken place in the U.S. or Canada with ethnic minority undergraduate students, but Chen et al. (2008) referenced the importance of considering different groups of people affected by migration trends. To understand the effects of contact with either the majority or minority ethnic culture on different groups, Chen et al. (2008) measured acculturation effects on psychological adjustment for three different groups: immigrants (Chinese immigrants permanently relocated to Hong Kong), sojourners (Filipino domestic workers in Hong Kong, temporarily relocated for an undetermined amount of time), and individuals of the majority culture who come into contact with a second cultural group or language within their original culture (Chinese and Hong Kong university students in multicultural multilingual settings). This study contributed knowledge for two groups rarely considered in previous literature: sojourners and individuals of the majority culture. Given that immigrants versus sojourners may have different motivations and perspectives on adjusting to the new culture due to differences in their length of stay, BII was an important factor to measure. The results showed that BII was a significant predictor of psychological adjustment for immigrants and individuals of the majority culture. The same effect of BII on psychological adjustment was not found for sojourners, potentially due to their indefinite length of stay. Instead, an important predictor of psychological adjustment for sojourners was performancerelated skills, such as language proficiency.

Extending upon language proficiency and cognition frameworks, Schwartz et al. (2014) further examined cultural frame switching by randomly assigning bilingual first-generation (born 
outside of the U.S.) and second-generation (parents born outside the U.S. but participant born in the U.S.) immigrant Hispanic college students to complete acculturation measures in either Spanish or English. The results showed measurement invariance across language of assessment. Latent mean differences, however, reveal slightly different results than what the authors initially hypothesized. For example, participants in the English language condition reported higher U.S. cultural behaviors as well as higher Hispanic cultural behavior than those in the Spanish language condition. Language use across the two domains (U.S. vs. Hispanic practices) did not differ across language conditions, which counters part of the hypotheses. Yet the authors remarked that despite evidence to suggest the appropriateness of pooling across language, these findings serve as a foundation for further research into specific conditions under which assessment language can be pooled. This conclusion was based on a fully bilingual sample within a highly bicultural context. Measurement equivalence found in this study may not be generalizable to individuals who are not fluent in both languages, do not live in a bicultural environment, or do not attend university (Schwartz et al., 2014).

\section{Validity Issues}

Participants are sometimes given the option to self-select into the language in which to complete the assessment. Some studies, however, ignore this self-selection factor and aggregate participant data, consequently also ignoring language (Schwartz et al., 2014). When studying acculturation, or a culturally based construct, there are four main threats to validity when selfselection into the language of the administered assessment is ignored (Schwartz et al., 2014). The four threats Schwartz et al. (2014) delineate are cultural frame switching, stereotype threat, translation quality, and language competency. 
First, cultural frame switching occurs when people unconsciously switch their behavior, frame of thinking, language preference, etc. when primed with certain cultural cues. By priming people with certain contextual cues (e.g., language, symbols, behaviors, or mannerisms) from either their heritage culture or culture of exposure, their responses towards culturally related questions will differ. Answering questions given ambiguous stimuli is influenced by whichever cultural schemata has been activated. Benet-Martínez et al. (2002) demonstrated that BII was a moderator in the effect of priming cues, such that bicultural participants with high BII responded in a way that was congruent to both cultures. Conversely, there was a reverse priming effect for participants with low BII, who responded in a manner consistent with the opposite culture of the given priming cues. For example, participants with low BII who were given American cues responded with a characteristically Asian behavior.

Luna et al. (2008) conducted three studies that examined how language triggers frame switching in a Hispanic female sample. The researchers also considered implicit attitudes and conceptual associations between stimuli across languages, as there may be moderating effects of stimuli words across languages. They make the distinction between people who are bicultural versus people who are bilingual but not necessarily bicultural (monocultural). Bicultural refers to the internalization of two cultures, often implying proficiency and/or fluency in the associated languages (Luna et al., 2008). It is possible for individuals to learn a second language but are not subsequently considered bicultural. The results suggest that cultural frame switching only occurs for bicultural individuals; the same results were not found for bilingual monoculturals. This is because cultural frame switching involves, in addition to language, identity and behavior. Luna et al. (2008) argue that cultural frame switching is due to gained experiences which form a 
cultural framework, a domain that cannot be built without direct experience of a language's cultural context.

Second, stereotype threat refers to anxiety or concern a person may experience that could potentially negatively affect their performance, thereby confirming a negative stereotype for that social group (Schwartz et al., 2014; Steele, 1997). Similar to cultural frame switching, stereotype threat involves activating schemata for a certain culture, which often includes the stereotypes associated with that group. In some cases, however, stereotype threat may promote avoiding both assimilation as well as upholding one's ethnic culture. Consequently, results affected by stereotype threat may be opposite to what cultural frame switching may predict.

Third, translation quality threatens validity in that different translations of a measure may not necessarily be valid. Back-translating is an oft used method for creating different translations of a measure. Although measures are taken to ensure the intended meanings of items are not altered, final scores taken across languages may not always have the same meaning. To further exasperate the problem, O’Bryon and Rogers (2010) report that self-identified bilingual school psychologists who administer language proficiency assessments do not clearly identify the level of fluency in the second language, and often, assessments administered in the second language are given with discomfort, indicating a lack of proper training and consideration of translation measures in acculturation assessments.

Fourth, language competency is a concern when self-selection is an option because there are always certain influences that affect selection of one assessment language over another. Some of these influences include, but are not limited to, language competency, comfortability, and social stigma. A likely reason for selecting a certain language is that the person is more fluent or comfortable in that language. On the other hand, there may be unspoken social 
pressures to improve or demonstrate competency in a language, so the language is selected despite non-proficiency.

\section{Discussion}

A persisting trend in the literature is the difficulty in constructing a definitive way to measure acculturation. As there are different facets of culture, so there are also many ways of assessing acculturation. This is both a strength and a limitation. The strength lies in the continuous examination of acculturation from a myriad of perspectives, each researcher offering a slightly different view adds richness and diversity to a field so grounded in multiculturalism. With the many different subgroups to consider, there have been approaches for scale development. First, researchers can attempt to develop a different scale for every subculture. Given the vast number of subcultures, however, many minority cultures composed of a small number of members may be neglected. There is also the ever-present issue of generalizability to other similar subcultures. Second, the introduction of measuring acculturation towards a panethnic identification seems to be a promising take on measuring individual subcultures. There is, however, always a risk of becoming too dependent on measuring pan-ethnic identity, attempts on overgeneralizing, and thus loss of levels in subcultural diversity. Third, changes in the direction of variable selection shifted from using demographic variables (e.g., language use, media preference, food selection, friends, etc.) to considering psychological constructs (e.g., emotions, cognition, attitudes, beliefs) to an integrated view of both (i.e., cultural frame switching). Understanding general psychological constructs and the cues that could be used for bicultural people to switch from one frame to another are conducive to gaining a more comprehensive picture of acculturation and/or biculturalism. 


\section{Implications}

Although opportunities to interact with other cultures serve to enrich the human experience, there is the reality of disparities (e.g., economic, educational, health, etc.) between different ethnic groups that may be exasperated by dependency on testing for decision making if different cultural norms are not considered. Assessments are administered to make decisions for a variety of domains, including (but not limited to) assessing educational outcomes, aptitude, personality, mental and physical health, well-being, and job selection. Therefore, correctly assessing acculturation is a step in gaining a better understanding of how to harmonically interact in multicultural settings.

\section{Limitations}

As with any study, there remain gaps in the literature to be filled and limitations to be addressed. First, since measuring acculturation is often used to help determine needs for important aspects of people's lives, we cannot just focus on acculturation, per se. Rather, there is a need to understand that a bi- or multicultural identity exists. In order to best capture bi- or multicultural dimensions of identity, when dealing with people of different cultures, we must also account for language barriers, differences in proficiency of language, and comfortability in operating within certain cultural contexts, as cultural cues may trigger different frameworks for response (culture frame switching). Thereby, in order to capture the most valid information for making decisions, we have to be cognizant of the effects of language in assessment. One of the challenges, however, is that of bi- or multilingual people who exhibit different levels of proficiency in a language. Furthermore, there is the consideration of self-selection and reasons for opting to take an assessment using a certain language over another, which cannot be ignored (e.g., Schwartz et al., 2014). 
Second, the literature lacks research studies that examine patterns of change, fluidity and transition between profiles. Of the reviewed studies, few, if any, incorporate statistical and methodological techniques that measure change in acculturation status over time (e.g., latent transition analysis, latent profile analysis). Along with using longitudinal designs, there is also a lack of consideration for external factors. One example is examining how societal stereotypes, attitudes, and perceptions of a certain culture shift over time (e.g., traditional aspects of a minority culture become heavily endorsed by the majority culture, consequently casting the minority culture in a positive light). Similarly, given the spread of the internet, the role and influence of digital media and social media (access to online resources, communities, cultural influences) should be examined. With digital media, representation of previously underrepresented ethnic minority groups may bring cultural awareness to the majority. With social media, people of ethnic minority groups have access to online resources, communities, and cultural influences that may serve to strengthen their ethnic group identification.

Third, acculturation, by definition, should occur for people of both the minority and majority ethnic groups through contact. Given current political disagreements in different multicultural contexts, it would be beneficial to consider how members of an ethnic minority group affect perceptions, attitudes, and opinions of members in the majority culture. Unfortunately, not much work has been done on how cross-cultural interactions have affected members of the majority cultural group (with the exception of Chen et al., 2008). People of both the ethnic minority and majority make up the entire population; thus, changes in acculturation for the majority group when in contact with people from diverse cultures should be taken in to account to grasp a fuller understanding of interpersonal communication, adjustment, and social 
processing. Understanding how mindsets shift with consistent exposure to an ethnic minority culture could serve to ameliorate strained political relations.

Overall, the articles reviewed in this paper suggest that trends and patterns in acculturation should be continually revisited. As globalization continues to influence human migration over time, so then must the measures for understanding acculturation be revised to reflect shifts in demographics, historical contexts, and cultural and societal perceptions and attitudes of different ethnic groups as people of different cultures continue to coexist, interact, and intermingle. 


\section{References}

Abe-Kim, J., Okazaki, S., \& Goto, S. G. (2001). Unidimensional versus multidimensional approaches to the assessment of acculturation for Asian American populations. Cultural Diversity and Ethnic Minority Psychology, 7(3), 232-246. https://doi.org/10.1037//1099$\underline{9809.7 .3 .232}$

Basilio, C. D., Knight, G. P., O’Donnell, M., Roosa, M. W., Gonzales, N. A., Umaña-Taylor, A. J., \& Torres, M. (2014). The Mexican American Biculturalism Scale: Bicultural comfort, facility, and advantages for adolescents and adults. Psychological Assessment, 26(2), 539-554. https://doi.org/10.1037/a0035951

Benet-Martínez, V., Leu, J., Lee, F., \& Morris, M. W. (2002). Negotiating biculturalism: Cultural frame switching in biculturals with oppositional versus compatible cultural identities. Journal of Cross-Cultural Psychology, 33(5), 492-516. https://doi.org/10.1177/0022022102033005005

Berry, J. W. (1980). Acculturation as varieties of adaptation. In A. Padilla (Ed.), Acculturation: Theory, models, and some new findings (pp. 9-25). Westview.

Chen, S. X., Benet-Martínez, V., \& Bond, M. H. (2008). Bicultural identity, bilingualism, and psychological adjustment in multicultural societies: Immigration-based and globalizationbased acculturation. Journal of Personality, 76(4), 803-838. https://doi.org/10.1111/j.1467-6494.2008.00505.x

Chia, A.-L., \& Costigan, C. L. (2006). A person-centered approach to identifying acculturation groups among Chinese Canadians. International Journal of Psychology, 41(5), 397-412. https://doi.org/10.1080/00207590500412227

Chung, R. H. G., Kim, B. S. K., \& Abreu, J. M. (2004). Asian American multidimensional 
acculturation scale: Development, factor analysis, reliability, and validity. Cultural Diversity and Ethnic Minority Psychology, 10(1), 66-80. https://doi.org/10.1037/1099$\underline{9809.10 .1 .66}$

Comas-Diaz, L., \& Grenier, J. R. (2002). Migration and acculturation. In J. Sandoval, C. L. Frisby, K. F. Geisinger, J. Scheuneman, \& J. R. Grenier (1997), Test interpretation and diversity: Achieving equity in assessment (pp. 213-240). American Psychological Association.

Cuéllar, I., Arnold, B., \& Maldonado, R. (1995). Acculturation rating scale for Mexican Americans-II: A revision of the original ARSMA scale. Hispanic Journal of Behavioral Sciences, 17(3), 275-304. https://doi.org/10.1177/07399863950173001

Cuéllar, I., Harris, L. C., \& Jasso, R. (1980). An acculturation scale for Mexican American normal and clinical populations. Hispanic Journal of Behavioral Sciences, 2, 199-217.

Cummins, J. (1982). Tests, achievement, and bilingual students. National Clearinghouse for Bilingual Education, 9, 2-9.

Diana v. California State Board of Education, No. C-70, RFT, (N. D. Cal. 1970).

Eytan, A., Jene-Petschen, N., \& Gex-Fabry, M. (2007). Bicultural identity among economical migrants from three south European countries living in Switzerland. Adaptation and validation of a new psychometric instrument. BMC Psychiatry, 7(17). https://doi.org/10.1186/1471-244X-7-17

Figueroa, R. A. (1989). Psychological testing of linguistic-minority students: Knowledge gaps and regulations. Exceptional Children, 56(2), 145-152. https://doi.org/10.1177/001440298905600206

Frisby, C. L. (1998). Culture and cultural differences. In J. Sandoval, C. L. Frisby, 
K. F. Geisinger, J. Scheuneman, \& J. R. Grenier (Eds), Test interpretation and diversity: Achieving equity in assessment (pp. 51-73). American Psychological Association.

Kang, S. M. (2006). Measurement of acculturation, scale formats, and language competence: Their implications for adjustment. Journal of Cross-Cultural Psychology, 37(6), 669-693. https://doi.org/10.1177/0022022106292077

Kim, B. S. K., \& Abreu, J. M. (2001). Acculturation measurement: Theory, current instruments, and future directions. In J. G. Ponterotto, J. M. Casas, L. A. Suzuki, \& C. M. Alexander (Eds.), Handbook of multicultural counseling (2nd ed., pp. 394-424). Sage.

King, J., \& Keane, E. (1992). Acculturation Scale for American Indian Adolescents: Voices of Indian teens project. University of Colorado Health Sciences Center.

Kroeber, A. L., \& Kluckhohn, C. (1952). Culture: A critical review of concepts and definitions. Vintage Books.

Lau v. Nichols, 414 U.S. 563 (1974).

Lechuga, J. (2008). Is acculturation a dynamic construct? The influence of method of priming culture on acculturation. Hispanic Journal of Behavioral Sciences, 30(3), 324-339. https://doi.org/10.1177/0739986308319570

Luna, D., Ringberg, T., \& Peracchio, L. A. (2008). One individual, two identities: Frame switching among biculturals. Journal of Consumer Research, Inc., 35, 279-293. https://doi.org/10.1086/586914

Marín, G. \& Gamba, R. J. (1996). A new measurement of acculturation for Hispanics: The Bidimensional Acculturation Scale for Hispanics (BAS). Hispanic Journal of Behavioral Sciences, 18(3), 297-316. https://doi.org/10.1177/07399863960183002

McLean, J. E. (1995). Improving education through action research: A guide for administrators 
THE NEBRASKA EDUCATOR, VOLUME 5

and teachers. Corwin Press.

Moyerman, D. R., \& Forman, B. D. (1992). Acculturation and adjustment: A meta-analytic study. Hispanic Journal of Behavioral Sciences, 14(2), 163-200. https://doi.org/10.1177/07399863920142001

O’Bryon, E., \& Rogers, M. R. (2010). Bilingual school psychologists' assessment practices with English language learners. Psychology in the Schools, 47(10), 1018-1034. https://doi.org/10.1002/pits.20521

Padilla, A. M. (2001). Issues in culturally appropriate assessment. In L. A. Suzuki, J. G. Ponterotto, \& P. J. Meller (Eds.), Handbook of multicultural assessment (2nd ed., pp. 527). Jossey-Bass.

Rohner, R. P. (1984). Toward a conception of culture for cross-cultural psychology. Journal of Cross-Cultural Psychology, 15, 111-138. https://doi.org/10.1177/0022002184015002002

Sandoval, J. (1998). Testing in a changing world: An introduction. In J. Sandoval, C. L. Frisby, K. F. Geisinger, J. Scheuneman, \& J. R. Grenier (Eds), Test interpretation and diversity: Achieving equity in assessment (pp. 3-16). American Psychological Association. https://doi.org/10.1037/10279-015

Schwartz, S. J., Benet-Martínez, V., Knight, G. P., Unger, J. B., Zamboanga, B. L., Des Rosiers, S. E., Stephens, D. P., Huang, S., \& Szapocznik, J. (2014). Effects of language of assessment on the measurement of acculturation: Measurement equivalence and cultural frame switching. Psychological Assessment, 26(1), 100-114. https://doi.org/10.1037/a0034717

Schwartz, S. J., \& Unger, J. B. (2010). Biculturalism and context: What is biculturalism, and when is it adaptive? Human Development, 53, 26-32. https://doi.org/10.1159/000268137 
Schwartz, S. J., \& Zamboanga, B. L. (2008). Testing Berry's model of acculturation: A confirmatory latent class approach. Cultural Diversity and Ethnic Minority Psychology, 14(4), 275-285. https://doi.org/10.1037/a0012818

Steele, C. M. (1997). A threat in the air: How stereotypes shape intellectual identity and performance. American Psychologist, 52, 613-629. https://doi.org/https://psycnet.apa.org/doiLanding?doi=10.1037/0003-066X.52.6.613

Sue, D. W., \& Sue, D. (1990). Counseling the culturally different. Wiley.

Suinn, R. M., Richard-Figueroa, K., Lew, S., \& Vigil, P. (1987). The Suinn-Lew Asian SelfIdentity Acculturation Scale: An initial report. Educational and Psychological Measurement, 47, 401-407. https://doi.org/10.1177/0013164487472012

Szapocznik, J., Scopetta, M. A., Arnalde, M., \& Kurtines W. (1978). Cuban value structure: Treatment implications. Journal of Consulting and Clinical Psychology, 46, 961-970. https://doi.org/10.1037/0022-006X.46.5.961

Triandis, H. C., \& Brislin, R. W. (1984). Cross-cultural psychology. American Psychologist, 39, 1006-1016. https://doi.org/10.1037/0003-066X.39.9.1006

Tsai, J. L., Ying, Y. W., \& Lee, P. A. (2000). The meaning of "being Chinese" and "being American": Variation among Chinese American young adults. Journal of Cross-Cultural Psychology,31, 302-332. http://dx.doi.org/10.1177/0022022100031003002

U.S. Census Bureau. (2018). QuickFacts. Retrieved from https://www.census.gov/quickfacts/fact/table/US/PST045218.

Van de Vijver, F. J. R., \& Phalet, K. (2004). Assessment in multicultural groups: The role of acculturation. Applied Psychology: An International Review, 53(2), 215-236. https://doi.org/10.1111/j.1464-0597.2004.00169.x 